\title{
Obstructive sleep apnea syndrome and hypertension: mechanism of the linkage and 24-h blood pressure control
}

\author{
Kazuomi Kario
}

Hypertensive patients with obstructive sleep apnea syndrome (OSAS) constitute a high-risk group for metabolic syndrome. OSAS directly induces negative intrathoracic pressure and decreases pulmonary stretch receptor stimulation, chemoreceptor stimulation, hypoxemia, hypercapnia and microarousal. These changes potentiate various risk factors, including the sympathetic nervous system, renin-angiotensin-aldosterone system and inflammation. Early detection and treatment of OSAS in asymptomatic hypertensive patients is essentially important to prevent hypertensive target organ damage and subsequent cardiovascular events. Continuous positive airway pressure (CPAP) therapy, a first-line treatment in hypertensive patients with moderate to severe OSAS, reduces ambulatory BP level, particularly during the sleep period, and midnight BP surge. However, individual differences in the BP-lowering effect of CPAP have been observed. OSAS hypertensive patients who do not tolerate CPAP remain at a high risk for cardiovascular disease because of negative intrathoracic pressure and need more aggressive antihypertensive treatment to achieve 24-h BP control with nocturnal BP $<120 / 70 \mathrm{~mm} \mathrm{Hg}$.

Hypertension Research (2009) 32, 537-541; doi:10.1038/hr.2009.73; published online 22 May 2009

Keywords: CPAP; noctural hypertension; obstructive sleep apnea; resistant hypertension

\section{INTRODUCTION}

Obstructive sleep apnea syndrome (OSAS) is a risk factor for hypertensive target organ damage and subsequent cardiovascular disease. Recent guidelines for the management of hypertension have stressed the importance of OSAS. ${ }^{1,2}$ In clinical practice, early detection of OSAS in atypical asymptomatic hypertension and management of 24-h blood pressure (BP) control, combined with continuous positive airway pressure (CPAP), are essentially important in reducing target organ damage and risk of cardiovascular events.

The review focuses on the mechanism linking OSAS with hypertension and target organ damage, and proposes a clinical process for the detection and management of OSAS in hypertensive patients.

\section{MECHANISM UNDERLYING THE LINK BETWEEN HYPERTENSION AND OSAS}

OSAS is a risk factor for hypertension-related cardiovascular diseases, including ischemic heart disease, heart failure, arrhythmias, large vessel disease and cerebrovascular disease. ${ }^{3}$ OSAS is associated with a particularly high frequency of cardiovascular events during the night; however, the daytime incidence of cardiovascular events associated with OSAS is also increasing. Some reports have shown that OSAS is frequently associated with sudden death and acute myocardial infarction during the night. ${ }^{4,5}$ Midnight BP surge occurring during apneic episodes may be directly related to the nocturnal occurrence of cardiovascular events.

There are various mechanisms of OSAS that augment hypertension and target organ damage (Figure 1). OSAS directly induces negative intrathoracic pressure and decreases pulmonary stretch receptor stimulation, chemoreceptor stimulation, hypoxemia, hypercapnia and microarousal. These changes alter the various risk factors for hypertension and cardiovascular disease.

Periodic nocturnal hypoxemia increases the oxidative stress to the body, which in turn induces inflammatory reactions and endothelial damage. $^{6-9}$ In OSAS patients, nitrogen monoxide production is decreased and flow-mediated dilation decreases with an increasing apnea-hypopnea index (AHI). CPAP attenuates the decrease of nitrogen monoxide production observed in OSAS. ${ }^{10}$ Blood levels of highsensitivity C-reactive protein, a marker of inflammation, are increased in OSAS and the degree of increase has been shown to be higher in OSAS patients with the non-dipper type of diurnal BP variation than in those with the dipper type. ${ }^{11}$ These data indicate that OSAS patients with the non-dipper/riser type of nocturnal hypertension are also at an increased risk of cardiovascular events. Ambulatory BP monitoring (ABPM) for evaluating nocturnal BP is therefore recommended in OSAS patients. Although the serum levels of C-reactive protein and 


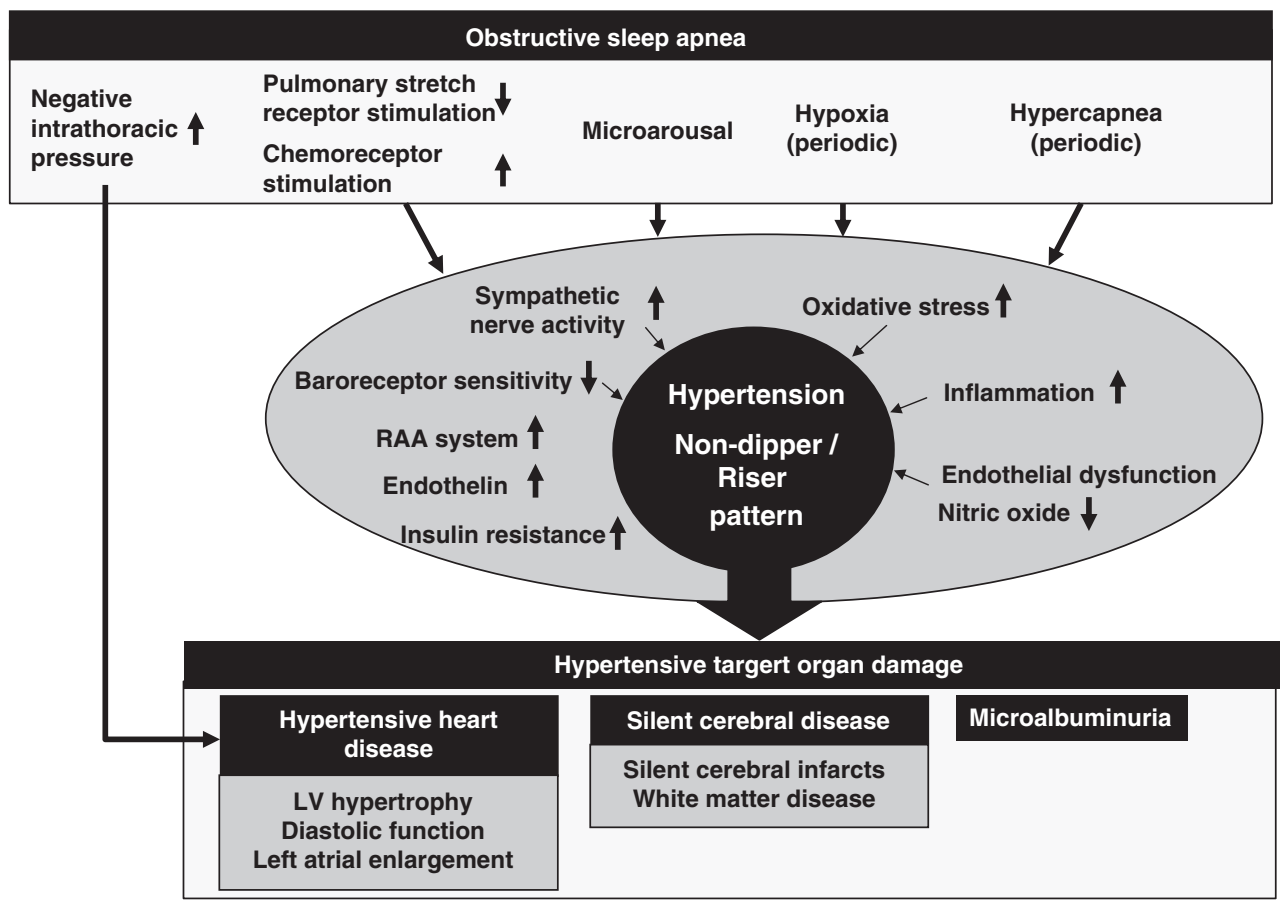

Figure 1 Mechanism of hypertension and target organ damage in obstructive sleep apnea syndrome. RAA, renin-angiotensin-aldosterone; LV, left ventricular.

interleukin-6 are increased in OSAS patients, CPAP attenuates the degree of increase of these parameters. ${ }^{12}$

OSAS patients have frequent awakenings at night and show elevated sympathetic nervous activity. As the pulmonary stretch receptor reflex, which suppresses sympathetic nervous activation, is decreased in OSAS, the balance of the autonomic nervous activity shows a tendency toward increased activity of the sympathetic nervous system. ${ }^{13}$ At the time of the nocturnal episodes of hypoxia, in particular, a burst of sympathetic nervous activity occurs, resulting in elevation of BP and heart rate. It is also widely recognized that apneic episodes in OSAS patients are exacerbated during rapid eye movement sleep, during which sympathetic nervous activity is increased. Increased sympathetic nervous activity may also cause coronary spasm and induce vasospastic angina pectoris. Furthermore, periodic negative intrathoracic pressure $(-80 \mathrm{~mm} \mathrm{Hg}$, at most), together with a midnight surge of BP, exerts mechanical stress on the ventricular and atrial walls, resulting in the development of left ventricular hypertrophy and left atrial remodeling and, consequently, an elevated risk of heart failure and atrial fibrillation. ${ }^{13}$ The incidence of eccentric cardiomegaly has been reported to be elevated in OSAS patients with left ventricular anomaly. ${ }^{14}$

A number of reports have shown that OSAS patients show decreased serum levels of adiponectin because of increased sympathetic nervous activity, ${ }^{15}$ insulin resistance, ${ }^{16}$ activity of the reninangiotensin-aldosterone (RAA) system ${ }^{17}$ and production of vasopressor hormones, and these changes are involved in the elevation of BP in OSAS patients. Plasma levels of endothelin-1 during the night in OSAS patients are increased in relation to BP and the severity of OSAS..$^{18}$

\section{MEDICAL CARE PROCESS OF HYPERTENSION TAKING INTO CONSIDERATION OSAS}

The clinical signs from which OSAS can be suspected are shown in Table $1 .^{1}$ It is a matter of course that typically obese patients with

\section{Table 1 Key words detecting obstructive sleep apnea syndrome}

Symptom Daytime sleepiness, reduced concentration, depression Indefinite complains (headache, malaise) at awakening or in the morning, marked snoring, frequent awakening during the night, nocturia, nocturnal dyspnea (feeling of suffocation)

Physical findings Obesity, micrognathia

Findings on Resistant morning hypertension including nocturnal hyperexamination tension, Left ventricular hypertrophy (particularly when the clinic and home BPs are normal), sleep-onset cardiovascular events (including arterial fibrillation and ventricular arrhythmia), metabolic syndrome

Abbreviation: BP, blood pressure.

hypertension who show symptoms such as daytime sleepiness, decreased concentration, depression and snoring at night should be suspected of having OSAS, but it is often the case that patients with hypertension do not have any subjective symptoms. It is therefore important to suspect OSAS and obtain a detailed history, even in the absence of subjective symptoms.

Portable pulse oximetry is useful for screening OSAS; however, accurate diagnosis and evaluation of OSAS severity can only be made by polysomnography. The severity of OSAS is classified on the basis of the apnea-hypopnea index (number of apneic/hypopneic episodes per hour): $5-15$, mild; $15-30$, moderate; 30 or more, severe.

The medical care process of masked hypertension, after taking OSAS into consideration, is shown in Figure 2. First, BP levels in the early morning are measured with a self-measured home BP monitoring. When the level is $135 / 85 \mathrm{~mm} \mathrm{Hg}$ or higher, the condition is regarded as morning hypertension and treated by an antihypertensive drug with the goal of obtaining normal morning BP levels 
Self-measured BP monitoring

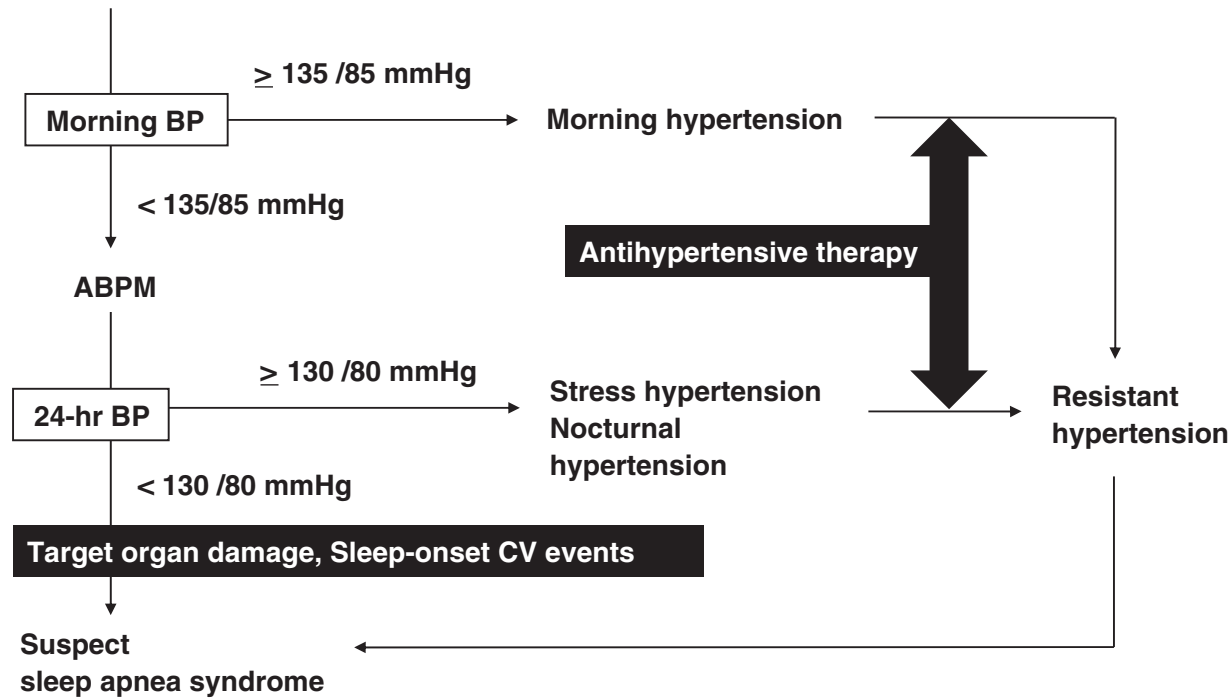

Figure 2 Detection of sleep apnea syndrome in clinical practice. BP, blood pressure; ABPM, ambulatory blood pressure monitoring, CV, cardiovascular.

$<135 / 85 \mathrm{~mm} \mathrm{Hg} .{ }^{19}$ When morning BP is lower than $135 / 85 \mathrm{~mm} \mathrm{Hg}$, $\mathrm{ABPM}$ is recommended. When mean $24-\mathrm{h} \mathrm{BP}$ is $130 / 80 \mathrm{~mm} \mathrm{Hg}$ or more, cases in which the daytime BP is high $(\geqslant 135 / 85 \mathrm{~mm} \mathrm{Hg})$ are considered to have daytime stress-induced hypertension. Cases in which nocturnal BP is high $(\geqslant 120 / 70 \mathrm{~mm} \mathrm{Hg})$ are considered to have nocturnal hypertension, and antihypertensive therapy targeted at these conditions is administered. ${ }^{19}$ When patients have nocturnal/ morning resistant hypertension and nocturnal or morning BP cannot be controlled, it is important to suspect OSAS. ${ }^{19}$

Moreover, in patients with a past history of nocturia, nocturnal dyspnea (a sensation of asphyxia) and nocturnal cardiovascular events (myocardial infarction, cerebral stroke, acute aortic dissection or supraventricular and ventricular arrhythmia) in spite of normal clinic $\mathrm{BP}$ readings, OSAS must be suspected. Even in patients in whom 24-h BP levels are normal at $<130 / 80 \mathrm{~mm} \mathrm{Hg}$, OSAS should be suspected when there is a past history and evidence of advanced target organ damage, particularly left ventricular hypertrophy, which is likely to be influenced by pressure load on the left ventricle. In OSAS, strong pressure load is placed on the left ventricular wall caused by periodic negative intrathoracic pressure during the episodes of apnea, leading to the development of hypertensive heart diseases, even when 24-h $\mathrm{BP}$ readings evaluated by $\mathrm{ABPM}$, including nocturnal BP levels, are normal.

\section{TREATMENT OF HYPERTENSION ASSOCIATED WITH OSAS}

\section{Non-drug therapy}

Weight loss is most effective in obese OSAS patients. As deterioration of OSAS occurs with alcohol intake, moderate drinking is to be recommended. Smokers are advised to quit smoking.

\section{CPAP therapy}

In hypertensive patients with moderate to severe OSAS (AHI >20), CPAP therapy is attempted as a first-line treatment (Figure 3). CPAP therapy exerts a BP-lowering effect, decreases nocturnal BP surge and improves cardiovascular prognosis in many OSAS patients. In a clinical trial conducted to compare the BP-lowering effect of CPAP and oxygen therapy, BP decreased only in the CPAP group. ${ }^{20}$ It is therefore suggested that the BP-lowering effect of CPAP is not related to improvement of nocturnal hypoxemia alone.

According to the meta-analysis that included 16 randomized controlled trials and involved 818 OSAS patients, when comparing the effects of CPAP on BP over at least 2 weeks with placebos (simulated CPAP in eight patients, drug therapy in four patients and conservative therapy in four patients), the mean $\mathrm{BP}$ reduction with CPAP was $-2.46 \mathrm{~mm} \mathrm{Hg}$ ( $95 \%$ confidence interval $(\mathrm{CI}):-4.31$ to $-0.62 \mathrm{~mm} \mathrm{Hg}$ ) for systolic BP and $-1.83 \mathrm{~mm} \mathrm{Hg}$ (95\% CI: -3.05 to $-0.61 \mathrm{~mm} \mathrm{Hg}$ ) for diastolic BP. ${ }^{21}$ Thus, the BP-lowering effect of CPAP is considered to be slight, taking into account the mean BP level in the study population.

Individual differences in the effect of CPAP have been observed; the BP-lowering effect of CPAP has been reported to be favorable in hypertensive patients with the following characteristics (Table 2): higher BP levels, untreated hypertension, nocturnal hypertension and resistant hypertension. ${ }^{21-24}$ In patients with nocturnal hypertension of the non-dipper/riser type in particular, BP levels during sleep are more selectively decreased by CPAP and the condition improves to the normal dipper type in many cases. ${ }^{25}$ Moreover, 'midnight BP surge' observed during episodes of apnea, is also suppressed by CPAP therapy. ${ }^{26,27}$

In patients with nocturnal hypertension, severe OSAS $(\mathrm{AHI}>30)$ and high body mass index, ${ }^{21,28}$ CPAP has been reported to markedly reduce $\mathrm{BP}^{22}$ The presence or absence of daytime sleepiness also influences the BP-lowering effect of CPAP. In OSAS patients with less daytime sleepiness, the BP-lowering effect of CPAP on daytime BP may be low, ${ }^{28-30}$ and CPAP compliance would also be poor in such patients. To obtain a favorable BP-lowering effect with CPAP treatment, it is important to ensure favorable compliance with CPAP, use of CPAP for at least $3 \mathrm{~h}$ each night, ${ }^{22} 50 \%$ decrease of the $\mathrm{AHI}^{31}$ and prolonged periods of CPAP use. ${ }^{31}$

\section{Antihypertensive drugs}

Hypertensive patients with mild to moderate $(\mathrm{AHI}<20)$ or moderate to severe OSAS who do not tolerate CPAP will remain at high risk to cardiovascular diseases. Such patients should be considered as high 


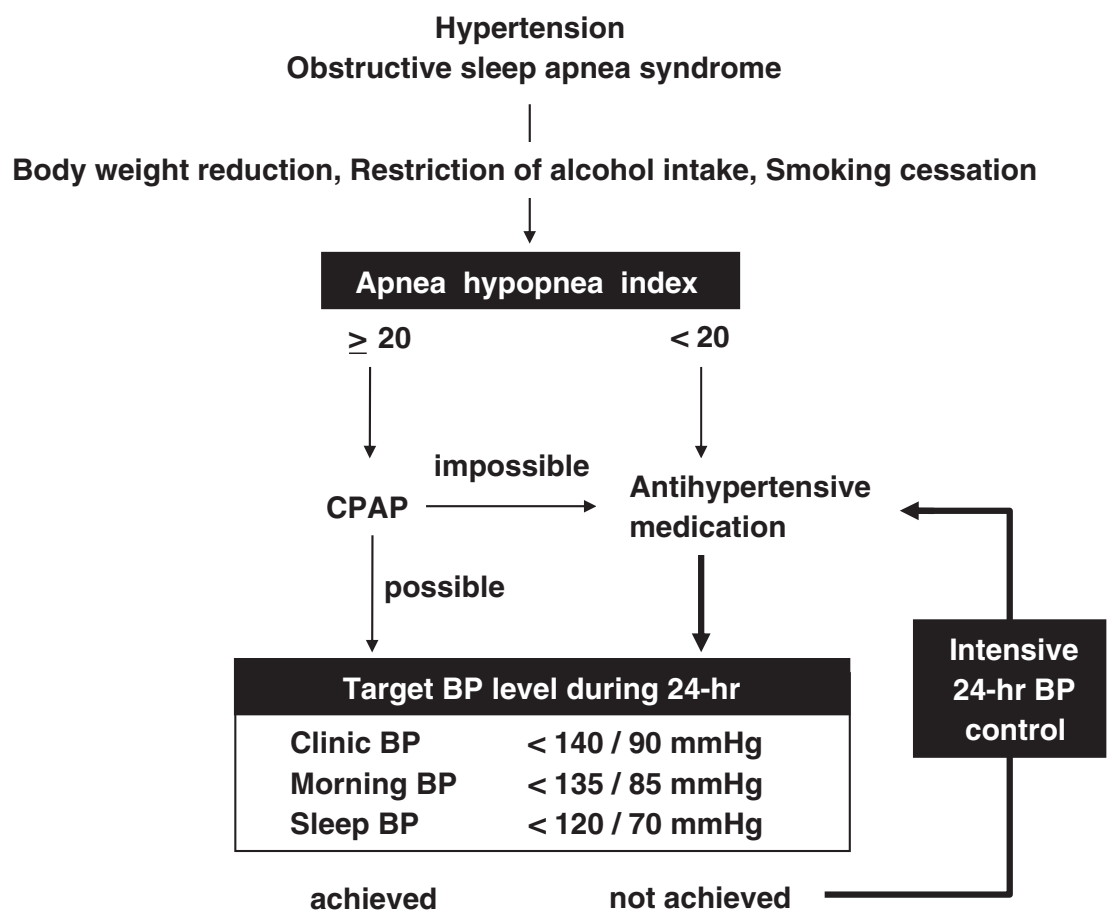

Figure 3 Management of hypertension with obstructive sleep apnea syndrome.

Table 2 Determinants of effective reduction in blood pressure by CPAP therapy in hypertensive patients with obstructive sleep apnea syndrome

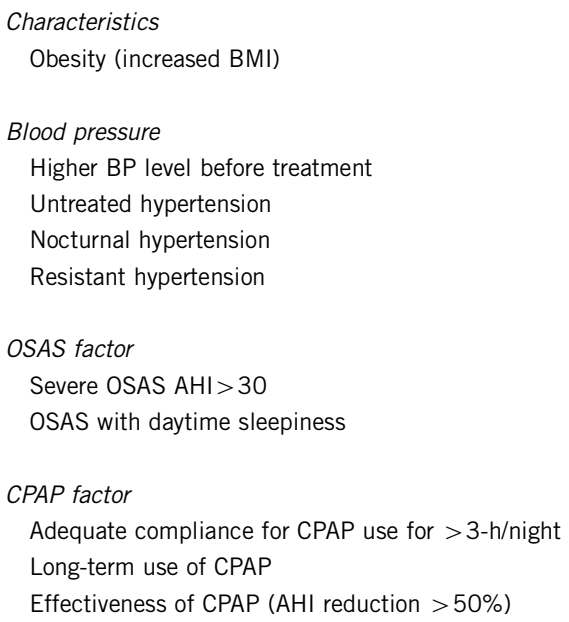

Abbreviations: AHI, apnea-hypopnea index; BMI, body mass index; CPAP, continuous positive airway pressure; OSAS, obstructive sleep apnea.

risk and must receive more aggressive antihypertensive therapy for intensive 24-h BP control (Figure 3). There is as yet insufficient evidence to set an optimal target BP level, but it is important to suppress nocturnal $\mathrm{BP}$ at least to the reference levels, that is, 120/ $70 \mathrm{~mm} \mathrm{Hg},{ }^{1}$ taking into consideration the increase in the negative intrathoracic pressure load during apneic episodes on the thoracic aorta and heart (the level may reach $-80 \mathrm{~mm} \mathrm{Hg}$ ).

There is also as yet insufficient evidence to suggest whether any specific class of antihypertensive drugs must be used to treat hypertension associated with OSAS. No change of the AHI is observed with any class of antihypertensive drugs, including $\alpha$-methyldopa and $\beta$ blockers, which have central actions, Calcium (Ca) antagonists or angiotensin-converting enzyme (ACE) inhibitors, indicating that none of the known classes of antihypertensive drugs may exert any specific effect on OSAS itself. ${ }^{32,33}$ An assessment conducted on a small number of patients showed that $\beta$ blockers significantly reduced diastolic BP measured on clinical examination compared with $\mathrm{Ca}$ antagonists, ACE inhibitors, angiotensin receptor blockers and diuretics. Another report showed significant reduction of the nocturnal systolic and diastolic BP levels following treatment with $\beta$ blockers compared with $\mathrm{Ca}$ antagonists, ACE inhibitors and angiotensin receptor blockers, although there was no significant difference in the degree of reduction of daytime BP during awakening, nor any difference compared with diuretics. ${ }^{34}$ However, one study suggested that nocturnal BP level could only be minimally controlled by single drug administration, including $\beta$ blockers, although daytime BP levels could be reduced. ${ }^{35}$ Thus, no consensus has yet been established on the OSAS-specific efficacy of $\beta$-blockers. As the plasma aldosterone levels are increased in OSAS patients with resistant hypertension, it is considered that aldosterone blockers may be useful for the treatment of hypertension in these patients. From the viewpoint of suppression of target organ damage, OSAS patients, especially obese OSAS patients, show enhanced activity of the RAA system and a high frequency of left ventricular hypertrophy, suggesting that treatment with RAA system inhibitors might be useful in these patients. It has been suggested that diuretics improved laryngeal edema and then improved OSAS in hypertensive OSAS patients with heart failure. ${ }^{36}$ On the other hand, one study has suggested the possibility of dry cough induced by ACE inhibitors causing an inflammation of the upper airway and worsening OSAS itself in OSAS patients. ${ }^{37}$

\section{CONCLUSION}

Ambulatory BP measured by ABPM in OSAS patients often shows nocturnal hypertension with increased variations of BP. OSAS patients 
are recognized as a high-risk group for metabolic syndrome, attributable to obesity. Moreover, for resistant morning hypertension or nocturnal hypertension without typical symptoms in patients with left ventricular hypertrophy, even where ambulatory BP level is normal, it is important to suspect OSAS and carry out appropriate diagnosis and treatment.

\section{CONFLICT OF INTEREST}

The author declares no conflict of interest.

1 Ogihara T, Kikuchi K, Matsuoka H, Fujita T, Higaki J, Horiuchi M, Imai Y, Imaizumi T, Ito S, Iwao H, Kario K, Kawano Y, Kim-Mitsuyama S, Kimura G, Matsubara H, Matsuura H, Naruse M, Saito I, Shimada K, Shimamoto K, Suzuki H, Takishita S, Takahashi N, Tsuchihasi T, Uchiyama M, Ueda S, Ueschima H, Umemura S, Ishimitsu T, Rakugi H. The Japanese Society of Hypertension Guidelines for the Management of Hypertension (JSH 2009). Hypertens Res 2009; 32: 3-107.

2 Mancia G, De Backer G, Dominiczak A, Cifkova R, Fagard R, Germano G, Grassi G, Heagerty AM, Kjeldsen SE, Laurent S, Narkiewicz K, Ruilope L, Rynkiewicz A, Schmieder RE, Boudier HA, Zanchetti A, Vahanian A, Camm J, De Caterina R, Dean V, Dickstein K, Filippatos G, Funck-Brentano C, Hellemans I, Kristensen SD, McGregor K, Sechtem U, Silber S, Tendera M, Widimsky P, Zamorano JL, Erdine S, Kiowski W, Agabiti-Rosei E, Ambrosioni E, Lindholm LH, Viigimaa M, Adamopoulos S, AgabitiRosei E, Ambrosioni E, Bertomeu V, Clement D, Erdine S, Farsang C, Gaita D, Lip G, Mallion JM, Manolis AJ, Nilsson PM, O'Brien E, Ponikowski P, Redon J, Ruschitzka F, Tamargo J, van Zwieten P, Waeber B, Williams B, Management of Arterial Hypertension of the European Society of Hypertension; European Society of Cardiology. 2007 Guidelines for the Management of Arterial Hypertension: The Task Force for the Management of Arterial Hypertension of the European Society of Hypertension (ESH) and of the European Society of Cardiology (ESC). J Hypertens 2007; 25: 1105-1187.

3 Somers VK, White DP, Amin R, Abraham WT, Costa F, Culebras A, Daniels S, Floras JS, Hunt CE, Olson LJ, Pickering TG, Russell R, Woo M, Young T, American Heart Association Council for High Blood Pressure Research Professional Education Committee, Council on Clinical Cardiology; American Heart Association Stroke Council; American Heart Association Council on Cardiovascular Nursing; American College of Cardiology Foundation. Sleep apnea and cardiovascular disease: an American Heart Association/american College Of Cardiology Foundation Scientific Statement from the American Heart Association Council for High Blood Pressure Research Professional Education Committee, Council on Clinical Cardiology, Stroke Council, and Council On Cardiovascular Nursing. In collaboration with the National Heart, Lung, and Blood Institute National Center on Sleep Disorders Research (National Institutes of Health). Circulation 2008; 118: 1080-1111.

4 Gami AS, Howard DE, Olson EJ, Somers VK. Day-night pattern of sudden death in obstructive sleep apnea. N Engl J Med 2005; 352: 1206-1214.

5 Kuniyoshi FH, Garcia-Touchard A, Gami AS, Romero-Corral A, van der Walt C, Pusalavidyasagar S, Kara T, Caples SM, Pressman GS, Vasquez EC, Lopez-Jimenez F, Somers VK. Day-night variation of acute myocardial infarction in obstructive sleep apnea. J Am Coll Cardiol 2008; 52: 343-346.

6 Kato M, Roberts-Thomson P, Phillips BG, Haynes WG, Winnicki M, Accurso V, Somers VK. Impairment of endothelium-dependent vasodilation of resistance vessels in patients with obstructive sleep apnea. Circulation 2000; 102: 2607-2610.

7 Atkeson A, Yeh SY, Malhotra A, Jelic S. Endothelial function in obstructive sleep apnea. Prog Cardiovasc Dis 2009; 51: 351-362.

8 Lavie L. Oxidative stress - a unifying paradigm in obstructive sleep apnea and comorbidities. Prog Cardiovasc Dis 2009; 51: 303-312.

9 McNicholas WT. Obstructive sleep apnea and inflammation. Prog Cardiovasc Dis 2009; 51: 392-399.

10 Noda A, Nakata S, Koike Y, Miyata S, Kitaichi K, Nishizawa T, Nagata K, Yasuma F, Murohara T, Yokota M. Continuous positive airway pressure improves daytime baroreflex sensitivity and nitric oxide production in patients with moderate to severe obstructive sleep apnea syndrome. Hypertens Res 2007; 30: 669-676.

11 Ishikawa J, Hoshide S, Eguchi K, Ishikawa S, Pickering TG, Shimada K, Kario K. Increased low-grade inflammation and plasminogen-activator inhibitor-1 level in nondippers with sleep apnea syndrome. J Hypertens 2008; 26: 1181-1187.

12 Yokoe T, Minoguchi K, Matsuo H, Oda N, Minoguchi H, Yoshino G, Hirano T, Adachi M. Elevated levels of C-reactive protein and interleukin- 6 in patients with obstructive sleep apnea syndrome are decreased by nasal continuous positive airway pressure. Circulation 2003; 107: 1129-1134.
13 Bradley TD, Floras JS. Obstructive sleep apnoea and its cardiovascular consequences. Lancet 2009; 373: 82-93.

14 Chami HA, Devereux RB, Gottdiener JS, Mehra R, Roman MJ, Benjamin EJ, Gottlieb DJ. Left ventricular morphology and systolic function in sleep-disordered breathing: the Sleep Heart Health Study. Circulation 2008; 117: 2599-2607.

15 Lam JC, Xu A, Tam S, Khong PI, Yao TJ, Lam DC, Lai AY, Lam B, Lam KS, Mary SM. Hypoadiponectinemia is related to sympathetic activation and severity of obstructive sleep apnea. Sleep 2008; 31: 1721-1727.

16 Ip MS, Lam B, Ng MM, Lam WK, Tsang KW, Lam KS. Obstructive sleep apnea is independently associated with insulin resistance. Am J Respir Crit Care Med 2002; 165: 670-676.

17 Pratt-Ubunama MN, Nishizaka MK, Boedefeld RL, Cofield SS, Harding SM, Calhoun DA. Plasma aldosterone is related to severity of obstructive sleep apnea in subjects with resistant hypertension. Chest 2007; 131: 453-459.

18 Gjørup PH, Sadauskiene L, Wessels J, Nyvad O, Strunge B, Pedersen EB. Abnormally increased endothelin-1 in plasma during the night in obstructive sleep apnea: relation to blood pressure and severity of disease. Am J Hypertens 2007; 20: 44-52.

19 Kario K. Clinician's Manual on Early Morning Risk Management in Hypertension. Science Press: London, 2004, pp 1-68.

20 Norman D, Loredo JS, Nelesen RA, Ancoli-Israel S, Mills PJ, Ziegler MG, Dimsdale JE. Effects of continuous positive airway pressure versus supplemental oxygen on 24-h ambulatory blood pressure. Hypertension 2006; 47: 840-845.

21 Bazzano LA, Khan Z, Reynolds K, He J. Effect of nocturnal nasal continuous positive airway pressure on blood pressure in obstructive sleep apnea. Hypertension 2007; 50: 417-423.

22 Baguet JP, Barone-Rochette G, Pépin JL. Hypertension and obstructive sleep apnoea syndrome: current perspectives. J Hum Hypertens 2009 (e-pub ahead of print 8 January).

23 Logan AG, Tkacova R, Perlikowski SM, Leung RS, Tisler A, Floras JS, Bradley TD. Refractory hypertension and sleep apnoea: effect of CPAP on blood pressure and baroreflex. Eur Respir J 2003; 21: 241-247.

24 Martínez-García MA, Gómez-Aldaraví R, Soler-Cataluña JJ, Martínez TG, BernácerAlpera B, Román-Sánchez P. Positive effect of CPAP treatment on the control of difficult-to-treat hypertension. Eur Respir J 2007; 29: 951-957.

25 Akashiba T, Minemura H, Yamamoto H, Kosaka N, Saito O, Horie T. Nasal continuous positive airway pressure changes blood pressure 'non-dippers' to 'dippers' in patients with obstructive sleep apnea. Sleep 1999; 22: 849-853.

26 Shirasaki O, Yamashita S, Kawara S, Tagami K, Ishikawa J, Shimada K, Kario K. A new technique for detecting sleep apnea-related 'midnight' surge of blood pressure. Hypertens Res 2006; 29: 695-702.

27 Kario K. Obstructive sleep apnea syndrome: ambulatory blood pressure. Hypertens Res 2009 (in press).

28 Robinson GV, Langford BA, Smith DM, Stradling JR. Predictors of blood pressure fall with continuous positive airway pressure (CPAP) treatment of obstructive sleep apnoea (OSA). Thorax 2008; 63: 855-859.

29 Robinson GV, Smith DM, Langford BA, Davies RJ, Stradling JR. Continuous positive airway pressure does not reduce blood pressure in nonsleepy hypertensive OSA patients. Eur Respir J 2006; 27: 1229-1235.

30 Barbé F, Mayoralas LR, Duran J, Masa JF, Maimó A, Montserrat JM, Monasterio C, Bosch M, Ladaria A, Rubio M, Rubio R, Medinas M, Hernandez L, Vidal S, Douglas NJ, Agustí AG. Treatment with continuous positive airway pressure is not effective in patients with sleep apnea but no daytime sleepiness. A randomized, controlled trial. Ann Intern Med 2001; 134: 1015-1023.

31 Becker HF, Jerrentrup A, Ploch T, Grote L, Penzel T, Sullivan CE, Peter JH. Effect of nasal continuous positive airway pressure treatment on blood pressure in patients with obstructive sleep apnea. Circulation 2003; 107: 68-73.

32 Bartel PR, Loock M, Becker P, Robinson E, van der Meyden C, Rossouw S. Short-term antihypertensive medication does not exacerbate sleep-disordered breathing in newly diagnosed hypertensive patients. Am J Hypertens 1997; 10: 640-655.

33 Grote L, Wutkewicz K, Knaack L, Ploch T, Hedner J, Peter JH. Association between blood pressure reduction with antihypertensive treatment and sleep apnea activity. Am $J$ Hypertens 2000; 13: 1280-1287.

34 Kraiczi H, Hedner J, Peker Y, Grote L. Comparison of atenolol, amlodipine, enalapril, hydrochlorothiazide, and losartan for antihypertensive treatment in patients with obstructive sleep apnea. Am J Respir Crit Care Med 2000; 161: 1423-1428.

35 Planès C, Foucher A, Leroy M, Dartois N, Juste K, Baillart O, Raffestin B. Effect of celiprolol treatment in hypertensive patients with sleep apnea. Sleep 1999; 22: 507-513.

36 Bucca CB, Brussino L, Battisti A, Mutani R, Rolla G, Mangiardi L, Cicolin A. Diuretics in obstructive sleep apnea with diastolic heart failure. Chest 2007; 132: 440-446.

37 Cicolin A, Mangiardi L, Mutani R, Bucca C. Angiotensin-converting enzyme inhibitors and obstructive sleep apnea. Mayo Clin Proc 2006; 81: 53-55. 